\title{
Work-related thumb disorders in South African physiotherapists treating musculoskeletal conditions using manual therapy techniques
}

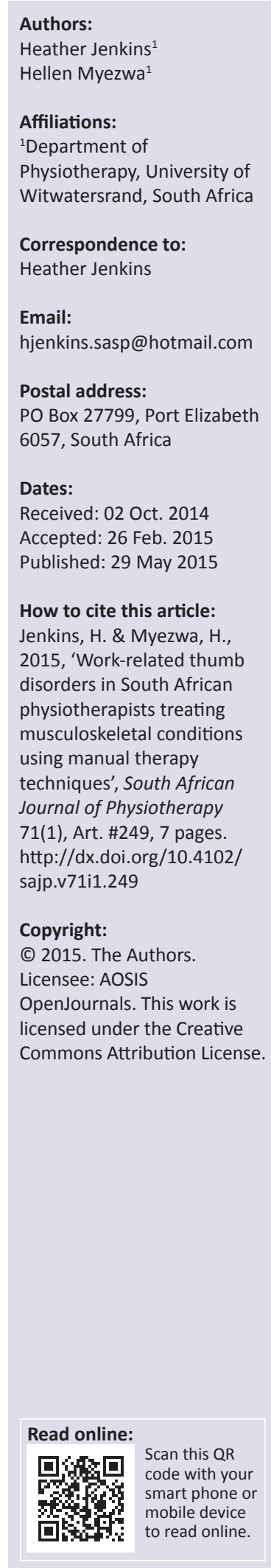

Research question: What is the prevalence of and factors associated with work-related thumb problems (WRTP) in South African physiotherapists treating musculoskeletal conditions using manual therapy techniques?

Design: A cross-sectional, descriptive study design was used and data were collected using two Internet-based questionnaires.

Participants: The sample size calculated for the study was 284 using 95\% confidence levels and a 5\% margin of error. There were 395 participants that were included in the study.

Outcome measures: The variables measured included demographic, employment, educational and occupational factors.

Results: The lifetime prevalence of WRTP in the physiotherapists was $65.3 \%$. The manual techniques that were significantly associated with WRTP in the respondents who reported thumb problems were all grades of transverse glides applied to the spine as well as grade II-IV unilateral and central posterior-anterior pressures to the spine. The factors that remained significantly associated with WRTP in all 395 respondents after regression analysis were the cervical treatment of up to six patients a day and hyperextension $>30^{\circ}$ of the non-dominant interphalangeal (IP) joint of the thumb.

Conclusion: This study confirms that a high percentage of physiotherapists using manual therapy techniques to treat musculoskeletal conditions are experiencing WRTP.

Recommendations: The development of a valid and reliable WRTP screening tool is needed to aid in the identification of physiotherapists at risk and thus in the primary prevention of WRTP. A longitudinal study which follows newly qualified physiotherapists is recommended to investigate a possible cause-effect relationship and preventative strategies for WRTP in physiotherapists.

\section{Introduction}

The World Health Organization (Luttman, Griefahn \& Caffier 2003) defines a work-related musculoskeletal disorder (WRMSD) as a form of ill health ranging from light transitory disorders to irreversible disabling injuries that are induced or aggravated by work and related circumstances. Despite physiotherapists' specialist knowledge on injury prevention, they are also prone to WRMSD. Several international studies (Bork et al. 1996; Holder et al. 1999) reported a 32\% lifetime prevalence of WRMSD in physiotherapists, whilst Cromie, Robertson and Best (2000) and West and Gardner (2001) reported a higher lifetime prevalence of WRMSD of 91\% and $55 \%$ respectively. African studies (Obembe et al. 2008; Useh, Igumbor \& Madzivire 2001) reported a lifetime prevalence of $78 \%$ whilst another study (Adegoke, Akodu \& Oyeyemi 2008) reported an annual prevalence of $91 \%$.

A hands-on approach of manual therapy is predominantly used in orthopaedic outpatient departments or private practices treating musculoskeletal disorders. Increased use of their hands puts these physiotherapists at risk of developing WRMSD of the wrists and hands (Barnes et al. 2011; Cromie et al. 2000; McMahon, Stiller \& Trott 2006; Snodgrass \& Rivett 2002; West \& Gardner 2001). The lifetime prevalence of work-related thumb problems (WRTP) ranged from $62.5 \%$ to $83 \%$ in studies focusing on wrist and thumb disorders (Barnes et al. 2011; McMahon et al. 2006; Wajon \& Ada 2003).

Barnes et al. (2011) investigated the prevalence of work-related wrist and thumb pain and the contributing risk factors amongst physiotherapists working in Bloemfontein, South Africa. 
The current study reported on WRTP only and included a national sample of physiotherapists.

\section{Methodology Design}

An observational study design was undertaken using a crosssectional, Internet-based questionnaire.

\section{Sample}

Sample size

A sample size was calculated using the formula sample size $=t^{2} \times p(1-p) / \mathrm{m}^{2}$, where $t=1.96$ for a $95 \%$ confidence level, $\mathrm{m}=$ margin of error at $5 \%$ (standard deviation of 0.05 ) and $p=0.65$ for a $65 \%$ prevalence of WRTP in a similar national study of WRTP in physiotherapists (McMahon et al. 2006). The sample size calculated (International Fund for Agricultural Development n.d.) was 350.

\section{Inclusion criteria}

South African physiotherapists registered with the South African Society of Physiotherapists (SASP) who were treating or have previously treated musculoskeletal conditions using manual therapy techniques were included in the study.

\section{Exclusion criteria}

Physiotherapists with structural deformities or injuries to the upper limbs as a result of non-work-related causes as well as those with diseases affecting the hands were excluded.

\section{Outcome measures}

A questionnaire was developed using information from similar studies (Barnes et al. 2011; McMahon et al. 2006; Wajon \& Ada 2003). It comprised demographic information, general questions on the area of practice; years worked as a physiotherapist; number of years or patients treated in the different body regions; and whether preventative education was received. Specific questions about WRTP regarding the thumb affected, symptoms, history of onset, aggravating factors and management strategies were included. The information on gender was elicited from a second questionnaire as it was excluded from the initial questionnaire because of a technical error. The questionnaire was validated for content by a panel of eight 'experts', who included physiotherapy lecturers and clinical physiotherapists. Further piloting of the questionnaire on 12 physiotherapists (questionnaires not included in the main study) was done to enhance the content validity of the questionnaire. The question in which the physiotherapists had to quantify the time spent on manual therapy was removed because of difficulty in quantifying time spent on manual techniques. McMahon et al. (2006) did not find a significant association between time spent and WRTP amongst 1562 physiotherapists of whom 65\% had WRTP.

\section{Ethical considerations}

Ethical clearance was obtained from the Human Research Ethics Committee at the University of the Witwatersrand (number M120429). All SASP-registered physiotherapists throughout South Africa were sent an Internet link to the survey and asked to complete the survey. A reminder was sent twice in the collection period between August 2012 and February 2013. In addition, physiotherapists belonging to the Orthopaedic Manipulative Therapy Group and the Sports Group received a link from their special interest group secretary which served as an additional reminder. Confidentiality was insured as the questionnaire did not request names, identity numbers and email addresses.

\section{Data analysis}

Data collected from the online questionnaire were exported to Microsoft Excel 2010 and then to Stata/IC 10.0 software to be analysed. Descriptive analysis was used to reduce the categorical data to frequencies and percentages. Tests for association were conducted using the Pearson's chi squared test for categorical data. Relationship of the data that were significantly associated with WRTP in all 395 respondents was tested in a regression analysis. Testing was done at the 0.05 level of significance.

\section{Results}

Of the 3523 physiotherapists who received the link, 456 responded to the invitation to participate in the study. Of these, 61 were excluded from the study on the grounds of missing data (27), structural deformities (21), diseases of the hand (8) and operations to the forearm and hand as a result of non-work-related factors (5), resulting in a final sample size of 395 . This represented $13 \%(n=45)$ more respondents than the calculated $(N=350)$ sample size.

The demographics of the sample are presented in Table 1. The majority of the respondents who responded to the questionnaire on gender $(60 \%, n=243)$ were female $(93 \%$, $n=226$ ). The lifetime prevalence of WRTP in the current study was $65.3 \%(n=258)$. The greatest majority respondents with WRTP was found in the age group 20-30 years $(70 \%, n=84)$.

Most respondents were employed full time at the time of the survey $(89.1 \%, n=352)$. The majority of respondents worked in work areas using manipulative therapy (Figure 1). The greatest prevalence of WRTP was found in physiotherapists working with orthopaedic outpatients and in work areas using manipulative therapy. Preventative education was only received by $47.1 \%(n=186)$ of the respondents. The majority of respondents received education on thumb protection at undergraduate level $(28.1 \%, n=111)$.

Table 2 represents the self-reported generalised hypermobility of respondents. Although a minority of physiotherapists reported generalised hypermobility for four out of the five parameters $(<15.4 \%, n<61)$, the majority of the respondents ( $>44 \%, n=174$ ) reported hypermobility of the joints of 
TABLE 1: Demographic characteristics including prevalence of work-related thumb problems.

\begin{tabular}{|c|c|c|c|c|c|}
\hline Demographic characteristic & Specification & Total respondents & $\%$ & Respondents with WRTP & $\%$ \\
\hline \multirow[t]{5}{*}{ Age in years } & $20-30$ & 120 & 30.4 & 84 & 70.0 \\
\hline & $31-40$ & 127 & 32.1 & 78 & 61.4 \\
\hline & $41-50$ & 88 & 22.3 & 55 & 62.5 \\
\hline & $51-60$ & 45 & 11.4 & 3 & 73.3 \\
\hline & $>60$ & 15 & 3.8 & 8 & 53.3 \\
\hline \multirow[t]{4}{*}{ Height in $\mathrm{cm}$} & $<150$ & 4 & 1 & 3 & 75.0 \\
\hline & $161-170$ & 164 & 41.5 & 108 & 65.8 \\
\hline & $171-180$ & 122 & 30.9 & 76 & 62.3 \\
\hline & $>180$ & 22 & 5.6 & 15 & 68.2 \\
\hline \multirow[t]{5}{*}{ Weight in kg } & $<50$ & 16 & 4.0 & 13 & 81.2 \\
\hline & $50-60$ & 129 & 32.6 & 85 & 65.9 \\
\hline & $61-70$ & 118 & 29.9 & 73 & 61.9 \\
\hline & $71-80$ & 74 & 18.7 & 52 & 70.3 \\
\hline & $>90$ & 19 & 4.8 & 12 & 63.1 \\
\hline \multirow[t]{4}{*}{ Race } & Asian & 20 & 5.1 & 14 & 70.0 \\
\hline & Black & 12 & 3.0 & 6 & 50.0 \\
\hline & Mixed & 27 & 6.8 & 16 & 59.3 \\
\hline & White & 336 & 85 & 222 & 66.1 \\
\hline \multirow[t]{9}{*}{ Qualifications } & OMPTG & 199 & 50.4 & 130 & 65.3 \\
\hline & Nil & 141 & 35.7 & 92 & 65.2 \\
\hline & Other & 48 & 12.1 & 9 & 18.7 \\
\hline & Sports and Exercise & 35 & 8.9 & 18 & 51.4 \\
\hline & Community Health & 13 & 3.3 & 9 & 69.7 \\
\hline & Paediatrics & 8 & 2.0 & 6 & 75.0 \\
\hline & Neurology/Neurosurgery & 6 & 1.5 & 5 & 83.3 \\
\hline & Respirology/Cardiothoracic & 4 & 1.0 & 3 & 75.0 \\
\hline & Orthopaedic Surgery & 2 & 0.5 & 2 & 100 \\
\hline
\end{tabular}

WRTP, work-related thumb problems; OMPTG, Orthopaedic Manipulative Physiotherapy Group.

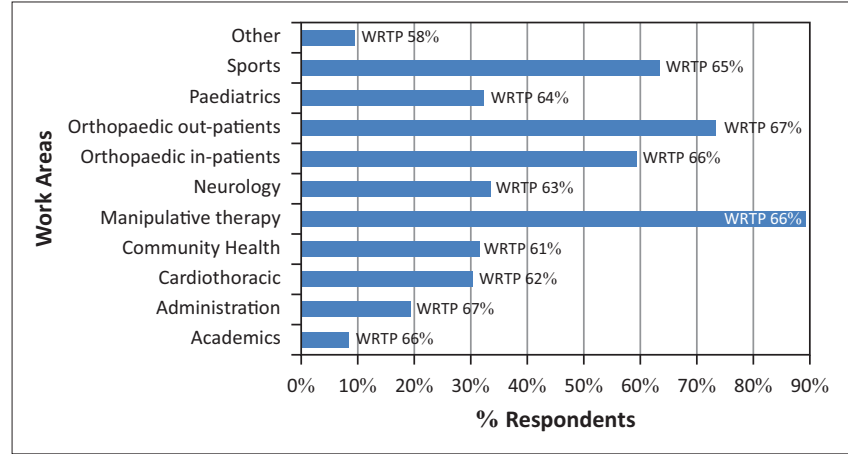

Note: Retroposition produced by (1) retroposition muscles: extensor pollicis longus (EPL), extensor pollicis brevis (EPB), abductor pollicis brevis (APB); (2) activity of the palmar oblique ligament; (3) articular contact (decreased). Physiological subluxation occurs if the thumb is pinched against the radial side of the hand.

$N=395$.

FIGURE 1: Work areas and prevalence of work-related thumb problems in respondents.

the thumbs between $0^{\circ}$ and $30^{\circ}$, as shown in Table 3 . The highest prevalence of WRTP was found in respondents with interphalangeal (IP) joint hyperextension greater than $30^{\circ}$ (dominant: $75.6 \%, n=62$; non-dominant: $78.5 \%, n=62$ ), as shown in Table 4.

The factors that were significantly associated with WRTP in all 395 respondents were put in a regression analysis (Table 5). Only hyperextension $>30^{\circ}$ of the non-dominant IP joint of the thumb and cervical spine treatment of up to six patients
TABLE 2: Distribution of generalised hypermobility and association with workrelated thumb problems.

\begin{tabular}{|c|c|c|c|c|}
\hline $\begin{array}{l}\text { Generalised } \\
\text { hypermobility }\end{array}$ & Category & Total & $\%$ & $p$-value \\
\hline \multirow{4}{*}{$\begin{array}{l}\text { Elbow hyperextension } \\
>10^{\circ}\end{array}$} & Yes: Dominant & 59 & 15.0 & 0.9 \\
\hline & Yes: Non-dominant & 46 & 11.6 & 0.5 \\
\hline & No & 334 & 84.5 & - \\
\hline & Total & 439 & 111.1 & - \\
\hline \multirow{4}{*}{$\begin{array}{l}\text { Knee hyperextension } \\
>10^{\circ}\end{array}$} & Yes: Dominant & 61 & 15.4 & 0.8 \\
\hline & Yes: Non-dominant & 54 & 13.7 & 0.02 \\
\hline & No & 332 & 84.0 & - \\
\hline & Total & 447 & 113.1 & - \\
\hline \multirow{4}{*}{$\begin{array}{l}\text { Passive flexion of thumb } \\
\text { to distal anterior forearm }\end{array}$} & Yes: Dominant & 56 & 14.2 & 0.5 \\
\hline & Yes: Non-dominant & 47 & 11.9 & 0.04 \\
\hline & No & 331 & 83.8 & - \\
\hline & Total & 434 & 109.9 & - \\
\hline \multirow{4}{*}{$\begin{array}{l}\text { Passive hyperextension } \\
\text { of MP joint of LF }\end{array}$} & Yes: Dominant & 52 & 13.2 & 0.8 \\
\hline & Yes: Non-dominant & 41 & 10.4 & 0.4 \\
\hline & No & 339 & 85.8 & - \\
\hline & Total & 432 & 109.4 & - \\
\hline \multirow{3}{*}{$\begin{array}{l}\text { Bend trunk forwards to } \\
\text { touch floor with knees } \\
\text { in extension }\end{array}$} & Yes & 116 & 29.4 & 0.7 \\
\hline & No & 279 & 70.6 & - \\
\hline & Totals & 395 & 100 & - \\
\hline
\end{tabular}

MP, metacarpophalangeal; LF, little finger.

a day remained significantly associated with WRTP. The factors that were not significantly associated with WRTP were all demographic factors, education factors and work areas of the physiotherapists $(p>0.05)$. 
TABLE 3: Reported thumb hypermobility and association with work-related thumb problems.

\begin{tabular}{|c|c|c|c|c|}
\hline Joint & Category & $n$ & $\%$ & $p$-value \\
\hline \multirow[t]{3}{*}{ IP joint hyperextension (CMC, MP in E): Dominant } & Yes, between $0^{\circ}$ and $30^{\circ}$ & 177 & 44.8 & 0.5 \\
\hline & Yes, $>30^{\circ}$ & 82 & 20.8 & 0.1 \\
\hline & No & 136 & 34.4 & - \\
\hline \multirow[t]{3}{*}{ IP joint hyperextension (CMC, MP in E): Non-dominant } & Yes, between $0^{\circ}$ and $30^{\circ}$ & 174 & 44.1 & 0.8 \\
\hline & Yes, $>30^{\circ}$ & 79 & 20.0 & 0.02 \\
\hline & No & 142 & 35.9 & - \\
\hline \multirow[t]{3}{*}{ MP joint hyperextension (CMC joint in E): Dominant } & Yes, between $0^{\circ}$ and $30^{\circ}$ & 183 & 46.3 & 0.2 \\
\hline & Yes, $>30^{\circ}$ & 54 & 13.7 & 0.6 \\
\hline & No & 158 & 40 & - \\
\hline \multirow[t]{3}{*}{ MP joint hyperextension (CMC joint in E): Non-dominant } & Yes, between $0^{\circ}$ and $30^{\circ}$ & 179 & 45.3 & 0.2 \\
\hline & Yes, $>30^{\circ}$ & 52 & 13.2 & 0.6 \\
\hline & No & 164 & 41.5 & - \\
\hline \multirow[t]{3}{*}{ MP joint hyperextension (CMC joint in F): Dominant } & Yes, between $0^{\circ}$ and $30^{\circ}$ & 196 & 49.6 & 0.2 \\
\hline & Yes, $>30^{\circ}$ & 54 & 13.7 & 0.2 \\
\hline & No & 145 & 36.7 & - \\
\hline \multirow[t]{3}{*}{ MP joint hyperextension (CMC joint in F): Non-dominant } & Yes, between $0^{\circ}$ and $30^{\circ}$ & 194 & 49.1 & 0.1 \\
\hline & Yes, $>30^{\circ}$ & 53 & 13.4 & 0.1 \\
\hline & No & 148 & 37.5 & - \\
\hline
\end{tabular}

IP, interphalangeal; CMC, carpometacarpal; MP, metacarpophalangeal; E, extension; F, flexion.

TABLE 4: Prevalence of work-related thumb problems in respondents who have thumb hypermobility $>30^{\circ}$.

\begin{tabular}{|c|c|c|c|c|c|c|c|c|c|c|c|c|}
\hline Category & $\begin{array}{l}\text { IP joint hyper E } \\
\text { (CMC/MP joints } \\
\text { in E): Dominant }\end{array}$ & $\%$ & $\begin{array}{l}\text { IP joint hyper E } \\
\text { (CMC/MP joints in } \\
\text { E): Non-dominant }\end{array}$ & $\%$ & $\begin{array}{l}\text { MP joint hyper E } \\
\text { (CMC joint in E): } \\
\text { Dominant }\end{array}$ & $\%$ & $\begin{array}{l}\text { MP joint hyper E } \\
\text { (CMC joint in E): } \\
\text { Non-dominant }\end{array}$ & $\%$ & $\begin{array}{l}\text { MP joint hyper E } \\
\text { (CMC joint in F): } \\
\text { Dominant }\end{array}$ & $\%$ & $\begin{array}{l}\text { MP joint hyper E } \\
\text { (CMC joint in F): } \\
\text { Non-dominant }\end{array}$ & $\%$ \\
\hline WRTP & 62 & 75.6 & 62 & 78.5 & 37 & 68.5 & 34 & 65.4 & 38 & 70.3 & 38 & 71.7 \\
\hline No WRTP & 20 & 24.4 & 17 & 21.5 & 17 & 31.5 & 18 & 34.6 & 16 & 29.7 & 15 & 28.3 \\
\hline Total & 82 & 100 & 79 & 100 & 54 & 100 & 52 & 100 & 54 & 100 & 53 & 100 \\
\hline
\end{tabular}

WRTP, work-related thumb problems; IP, interphalangeal; E, extension; CMC, carpometacarpal; MP, metacarpophalangeal; F, flexion.

TABLE 5: Relationship between significant factors and the presence of work-related thumb problems.

\begin{tabular}{|c|c|c|c|c|c|c|}
\hline Variable & Category & WRTP & $\%$ & Odds ratio (OR) & 95\% Confidence interval & $p$-value \\
\hline \multirow[t]{6}{*}{ Cervical spine treatment } & $1-2$ patients & 78 & 30.2 & 1 & - & - \\
\hline & $3-4$ patients & 125 & 48.8 & 1.9 & $1.2-3.0$ & 0.01 \\
\hline & 5-6 patients & 40 & 15.5 & 2.7 & $1.3-5.7$ & 0.01 \\
\hline & 7-8 patients & 9 & 3.5 & 1.3 & $0.4-4.0$ & 0.61 \\
\hline & 9-10 patients & 0 & 0 & - & - & - \\
\hline & $10-12$ patients & 0 & 0 & - & - & - \\
\hline \multirow[t]{3}{*}{ IP hyper-E (CMC/MP joints in E): Non-dominant } & No & 89 & 34.5 & 1 & - & - \\
\hline & Yes $\left(0^{\circ}-30^{\circ}\right)$ & 107 & 41.5 & 1.4 & $0.6-3.4$ & 0.4 \\
\hline & Yes $\left(>30^{\circ}\right)$ & 62 & 24.0 & 4.3 & $1.01-18.1$ & 0.05 \\
\hline \multirow[t]{3}{*}{ Knee hyper-E > $10^{\circ}$} & No & 209 & 81.0 & 1 & - & - \\
\hline & Dominant & 48 & 18.6 & 1.2 & $0.2-6.8$ & 0.8 \\
\hline & Non-dominant & 43 & 16.7 & 1.9 & $0.9-4.0$ & 0.1 \\
\hline \multirow[t]{2}{*}{ Thumb to distal forearm } & No & 209 & 81.0 & 1 & - & - \\
\hline & Non-dominant & 37 & 14.3 & 1.6 & $0.7-3.7$ & 0.3 \\
\hline
\end{tabular}

IP, interphalangeal; E, extension; CMC, carpometacarpal; MP, metacarpophalangeal.

Of the 258 physiotherapists who reported WRTP, 254 reported on the timing of the initial incident (Table 6). The majority $(40.5 \%, n=103)$ of these reported WRTP in their dominant thumbs within 5 years of graduating. Tables 7 and 8 show the prevalence and association of occupational factors with WRTP.

\section{Discussion}

The lifetime prevalence of WRTP for the physiotherapists in the current South African study was $65.3 \%(n=258)$. This is similar to the findings of a study in Australia by McMahon et al. (2006) which also reported on a national sample of physiotherapists and identified a lifetime prevalence of 65.3\% ( $n=961)$. Similarly, Barnes et al. (2011) reported a lifetime prevalence of wrist and thumb problems of $62.5 \%$ $(n=55)$ amongst South African respondents. The lifetime prevalence may have been lower if only thumb problems were reported.

Wajon and Ada (2003) reported a higher lifetime prevalence of WRTP $(83 \%, n=129)$. The different demographic samples 
TABLE 6: Timing of initial episode of work-related thumb problems.

\begin{tabular}{|c|c|c|c|c|}
\hline Timing of initial episode & Dominant thumb & $\%$ & Non-dominant thumb & $\%$ \\
\hline Undergraduate & 11 & 4.3 & 6 & 2.4 \\
\hline $0-5$ years after graduating & 103 & 40.5 & 69 & 27.2 \\
\hline $6-10$ years after graduating & 51 & 20.1 & 43 & 16.9 \\
\hline 10-20 years after graduating & 50 & 19.7 & 42 & 16.5 \\
\hline$>20$ years after graduating & 19 & 7.5 & 18 & 7.1 \\
\hline Do not know & 2 & 0.8 & 5 & 2.0 \\
\hline
\end{tabular}

$N=254$.

TABLE 7: Prevalence and association of occupational factors with work-related thumb problems.

\begin{tabular}{lccc}
\hline Work-related factor & $\boldsymbol{n}$ & $\boldsymbol{\%}$ & $\boldsymbol{p}$-value \\
\hline Soft tissue techniques using thumbs & 217 & 85.4 & $<0.001$ \\
Joint mobilisation/manipulation techniques & 211 & 83.1 & $<0.001$ \\
Treating large number of patients a day & 159 & 62.6 & $<0.001$ \\
Performing same task over and over & 156 & 61.4 & $<0.001$ \\
Increase in thumb use & 150 & 60.2 & $<0.001$ \\
Continue to work when thumb is injured & 143 & 56.3 & $<0.001$ \\
Inadequate training in thumb injury prevention & 80 & 31.5 & $<0.001$ \\
Working at or near physical limits & 44 & 17.3 & $<0.001$ \\
Not enough rest breaks & 43 & 16.9 & $<0.001$ \\
Percussion, vibration, shaking & 14 & 5.5 & $<0.001$ \\
\hline
\end{tabular}

TABLE 8: Prevalence and association of spinal mobilising techniques with work related thumb problems.

\begin{tabular}{llccc}
\hline Mobilisation technique & Category & $\boldsymbol{n}$ & $\mathbf{\%}$ & $\boldsymbol{p}$-value \\
\hline Central PA pressures & Grade I & 8 & 3.1 & 0.1 \\
& Grade II & 42 & 16.5 & 0.1 \\
& Grade III & 147 & 57.9 & $<0.001$ \\
& Grade IV & 112 & 44.1 & $<0.001$ \\
Unilateral PA pressures & Grade I & 6 & 2.4 & $<0.001$ \\
& Grade II & 47 & 18.5 & $<0.001$ \\
& Grade III & 153 & 60.2 & $<0.001$ \\
& Grade IV & 112 & 44.1 & $<0.001$ \\
Transverse glides & Grade I & 9 & 3.5 & $<0.001$ \\
& Grade II & 45 & 17.7 & $<0.001$ \\
& Grade III & 104 & 40.9 & $<0.001$ \\
& Grade IV & 82 & 32.3 & $<0.001$ \\
Mulligan techniques & Grade I & 2 & 0.01 & 0.5 \\
& Grade II & 29 & 33.8 & $<0.001$ \\
& Grade III & 66 & 26 & $<0.001$ \\
& Grade IV & 49 & 19.3 & $<0.001$ \\
\hline
\end{tabular}

$N=254$

$\mathrm{PA}$, posterior-anterio

could account for the higher lifetime prevalence. A crosssectional design including all physiotherapists using manual therapy techniques was used in the current study and in that of McMahon et al. (2006), whereas Wajon and Ada (2003) only included physiotherapists who had postgraduate qualifications in manipulative therapy. If only manipulative therapy graduates were included in this study, it would exclude the newly qualified physiotherapists who are more likely to develop WRMSD (Barnes et al. 2011; Cromie et al. 2000; West \& Gardner 2001).

In this study, newly qualified physiotherapists in the age group 20-30 years had a higher prevalence of WRTP (70\%, $n=84)$. The reason for the increased prevalence rates in the younger physiotherapists, according to Cromie et al. (2000), is the reluctance of younger physiotherapists to ask for help. It could also be linked to the increased workload or inability to stabilise their thumbs during the application of manual therapy techniques (Barnes et al. 2011; Buckingham, Das \& Trott, 2007; Walsh et al. 2011). The repetitive use of their thumbs during manual therapy techniques, especially on large and muscular patients, may pose a challenge which could possibly result in their thumb joints assuming hyperextended positions. Although this study did not find a significant association between WRTP and metacarpophalangeal (MP) joint hypermobility, McMahon et al. (2006) found a significant association between WRTP and MP and IP joint hyperextension $(p<0.001)$.

This study showed a significant association between WRTP and non-dominant thumb IP joint hyperextension $(p=0.02)$. Buckingham et al. (2007) and Wajon, Ada and Retshauge (2007) advocated that the thumb IP joint be positioned in extension or slight flexion to avoid WRTP, which is supportive of the finding. In contrast, Snodgrass and Rivett (2002) theorised that the lack of hyperextension of the IP joint during the application of posterior-anterior (PA) mobilisation to the spine would result in an increase in WRTP because the base of the thumb is positioned further away from the point of contact when the thumb pad is applying the pressure.

An understanding of the biomechanics of the different thumb joints is important in the prevention of WRTP. This is especially important when the biomechanics of the basal joint of the thumb (carpometacarpal joint) is considered. The osseous configuration of this joint allows for maximum mobility for the intricate functions of the hand; however, there are positions where there is incongruity of the joint surfaces (carpometacarpal joint in retroposition), resulting in decreased stability of the joint (Zancolli, Ziadenberg \& Zancolli 1987). For this reason, Atkinson and Maher (2004) questioned physiotherapists' use of the thumbs in the application of longitudinal pressure during manual therapy techniques. In order to lessen stress to the therapists' thumb joints, Hu, Hsu and Su (2009) recommended a position in which the thumb is supported by the neighbouring index finger. Jull (2011) describes a modified hand placement for the cervical posterior-anterior glide techniques in which the hands and thumbs are fixed and the force is generated by forearm (elbow) flexion and extension. Walsh et al. (2011), Buckingham et al. (2007) and Wajon et al. (2007) recommended support of the thumbs in the 
optimal position (thumb in opposition, MP and IP joints in extension or slight flexion) by using taping or splints, especially for physiotherapists who have hypermobility of the thumb joints.

Thistlethwaite's (2005) hypothesised a tendency toward hypermobility as a reason for a statistically significant difference $(p=0.005)$ in race groups; however, the current study found no significant association between WRTP and race. The difference in race demographics could explain this difference. In the current study, $85 \%$ of the respondents were white, whilst in Thistlethwaite's (2005) study over 50\% of the study population was Indian. She hypothesised that Indian physiotherapists, with a tendency toward hypermobility (Simpson 2006), would increase the tendency for joint instability and the development of WRTP. McMahon et al. (2006) reported a higher prevalence of WRTP in male physiotherapists, whereas the current study found a higher prevalence of WRTP in female physiotherapists. These differences could be explained by the difference in gender distribution in each context. In South Africa, physiotherapy is a female-dominated profession. Statistics obtained from the SASP for 2013 indicated that women represented $87.8 \%$ of the physiotherapists registered with the society. In this study, women represented $93 \%$ of the sample $(n=226$ of the 243 that responded to the gender questionnaire) whilst in the study by McMahon et al. (2006), men represented $22 \%$ of the sample. A significant association of WRTP in male physiotherapists working in orthopaedic outpatient departments was also found by McMahon et al. (2006), who attributed this to the fact that male physiotherapists are mostly employed in work areas requiring greater use of manual techniques.

The number of patients treated with cervical spine pathology was significantly associated with WRTP in the physiotherapists in this study. Alternatives such as the use of the pisiform are not usually possible in the cervical region because of the contours in this body region, whereas thoracic and lumbar regions lend themselves to the use of the heel of the hand for the stronger grades of movement. McMahon et al. (2006) as well as the current study also found a significant association between the presence of WRTP and the hands-on activity of manual therapy, trigger point therapy and massage. A greater percentage of respondents $(85.4 \%, n=217)$ said that soft tissue techniques aggravated their symptoms when compared to studies by McMahon et al. (2006), Wajon and Ada (2003) and Barnes et al. (2011) (75\%, $n=439 ; 69 \%, n=106$ and 65.5\%, $n=36$ respectively). Specific to the technique of passive accessory spinal joint mobilisation, $80 \%$ of the respondents in this study reported aggravation of WRTP. Wajon and Ada (2003) reported the same whilst McMahon et al. (2006) reported a slightly lower percentage $(75 \%)$. Only the current study reported on the grades of the techniques that aggravated WRTP.

A significant association was found between the presence of WRTP and grades III-IV Maitland central posterior-anterior glides, grades II-IV Mulligan techniques as well as all grades of the Maitland unilateral posterior-anterior glides and transverse glides to the spine $(p<0.001)$. An explanation could be that less force is used by the thumbs during the application of the grade I and II techniques compared to the force used in the stronger grades of movement. All Maitland unilateral posterior-anterior glides and transverse glides to the spine, however, were significantly associated with WRTP, perhaps because of the position of the thumb during the application of the technique. The thumb is less likely to be in a position of congruence (carpometacarpal [CMC] in opposition) when performing all grades of the transverse glides, resulting in more stress to the joint surfaces and surrounding soft tissue (Atkinson \& Maher 2004; Zancolli et al. 1987).

Other occupational factors associated with WRTP in physiotherapists treating musculoskeletal conditions using manual therapy techniques included the high, repetitive workload, treating a large numbers of patients daily, working with a current injury, working in sustained positions for prolonged periods, working in uncomfortable positions, inadequate preventative thumb injury training, inadequate rest periods and working at their physical limits. This was reported by $61 \%-80 \%$ of the respondents in the current study and other studies reporting on WRTP in physiotherapists (Barnes et al. 2011; McMahon et al. 2006; Wajon \& Ada 2003).

\section{Limitations of the study}

As this study was mainly retrospective in design, the information received was associated with a recall bias and based purely on the respondent physiotherapists' opinions, interpretation and memory. In addition to this, because of the cross-sectional design of the study, conclusions cannot be drawn regarding the cause or effect of thumb problems ascribed to work-related factors. Internet-based questionnaire bias may influence the validity of the results; Klovning, Sandvik and Hunskaar (2009) reported that a webbased survey reported a higher illness severity and attracted an age-based sample, namely younger respondents. Although the content validity of the questionnaire was addressed by a panel of 'experts', the test-retest reliability of the questionnaire was not verified although it should have been. Gender was excluded from the initial questionnaire because of a technical error. The results therefore give a close but not exact representation of the gender ratios for the study. However, they do align with the male to female ratio of the overall number of physiotherapists registered with the SASP.

\section{Conclusion and recommendations}

This study confirms that a high percentage of physiotherapists using manual therapy techniques to treat musculoskeletal conditions are experiencing WRTP. It would seem important that physiotherapists apply the same advice they would give patients who have musculoskeletal disorders. This advice, an important management strategy for WRTP, includes joint protection, job rotation and avoiding sustained postures or repetitive action (Glover 2002). 
A longitudinal study which follows newly qualified physiotherapists for at least two years is recommended to investigate a possible cause-effect relationship for WRTP in physiotherapists. Randomised controlled trials that investigate preventative strategies like taping or splints for the physiotherapists' thumbs are also recommended. If emerging research on this subject is communicated to undergraduate students and practising physiotherapists on an on-going basis, preventative strategies could be implemented. This would prevent physiotherapists from moving to another field of practice or, worse still, leaving the profession as a result of WRTP (McMahon et al. 2006; Snodgrass \& Rivett 2002; Wagon \& Ada 2003).

\section{Acknowledgements}

The authors wish to thank all physiotherapists who completed the questionnaire, as well as the lecturers and clinical physiotherapists who assisted with content validity of the questionnaire: Dr Douglas Maleka, Dr Benita Oliver, Dr Wendy-Ann Wood, Mrs Vaneshveri Naidoo, Mrs Nicola Roote, Mrs Desiree Perry and Mrs Felicity Zieseniss. The authors gratefully acknowledge PPK funding received from the South African Society of Physiotherapy.

\section{Competing interests}

The authors declare that they have no financial or personal relationships which may have inappropriately influenced them in writing this article.

\section{Authors' contributions}

H.J. (University of Witwatersrand) was the first author and researcher. The study was done in partial fulfilment of the degree MSc (Physiotherapy) Orthopaedics. H.M. (University of Witwatersrand) was the second author and study supervisor.

\section{References}

Adegoke, B.O.A., Akodu, A.K. \& Oyeyemi, A.L., 2008, 'Work-related musculoskeletal disorders among Nigerian physiotherapists', BMC Musculoskeletal Disorders 9, 112. http://dx.doi.org/10.1186/1471-2474-9-112

Atkinson, B.W. \& Maher, T., 2004, 'Thumb pain in physiotherapists: Biomechanical causes of pain and alternate and alternate methods of preventing distress in treatment', Journal of Manual \& Manipulative Therapy 12, 187-191. http://dx.doi.org/10.1179/106698104790825167

Barnes, R., Colyn, H.J., Moolman, C., Roux, Z., Shabort, D.J., Yzel, M.E. \& Raubenheimer J., 2011, 'The lifetime prevalence of work-related thumb and wrist pain among physiotherapists in Bloemfontein', Occupational Health South Africa July/ August, 16-22.

Bork, B.E., Cook, T.M., Rosencrance, J.C., Englhardt, K.A., Thomason, M.J., Wauford I.J. \& Worley, R.K., 1996, 'Work-related musculoskeletal disorders among physical therapists', Physical Therapy 76, 827-835
Buckingham, G., Das, R. \& Trott, P., 2007, 'Position of undergraduate students during mobilisation is poor: An observational study', Australian Journal of Physiotherapy 53, 55-59. http://dx.doi.org/10.1016/S0004-9514(07)70062-4

Cromie, J.E., Robertson, V.J. \& Best, M.O., 2000, 'Work-related musculoskeletal disorders in physical therapists: prevalence, severity, risks, and responses', Physical Therapy 80, 336-351.

Glover, W., 2002, 'Work-related strain injuries in physiotherapists: Prevalence and prevention of musculoskeletal disorders', Physiotherapy 88, 364-372. http:// dx.doi.org/10.1016/S0031-9406(05)60749-3

Holder, N., Clark, H., DiBlasio, M., Hughes, C.L., Scherpf, J.W., Harding, L. \& Shepard, K.F., 1999, 'Cause, prevalence and response to occupational musculoskeletal injuries reported by physical therapists and physical therapy assistants', Physical Therapy 79(7), 642-652.

Hu, M., Hsu, A. \& Su, F., 2009, 'Effect of general flexibility on thumb-tip force generation - Implication for mobilization and manipulation', Manual Therapy 14(5), 490-495. http://dx.doi.org/10.1016/j.math.2008.10.003

International Fund for Agricultural Development (IFAD), n.d., Calculating the sample size, viewed 12 February 2012, from http://www.ifad.org/gender/tools/hfs/ anthropometry/ant_3.htm

Jull, G., 2011, 'Towards preventing thumb pain from application of cervical manual therapy', Manual Therapy 16, 207-208. http://dx.doi.org/10.1016/j. math.2011.02.004

Klovning, A., Sandvik, H. \& Hunskaar, S., 2009, 'Web-based survey attracted agebiased sample with more severe illness than paper-based survey', Journal of Clinical Epidemiology 62, 1068-1074. http://dx.doi.org/10.1016/j.jclinepi. 2008.10.015

Luttman, A., Griefahn, B. \& Caffier, G., 2003, 'Preventing musculoskeletal disorders in the workplace', Protecting Workers Health Series No 5, viewed 15 February 2003, from http://www.who.int/occupational_health/publications/en/oehmsd3.pdf

McMahon, M., Stiller, K. \& Trott, P., 2006, 'The prevalence of thumb problems in Australian physiotherapists is high: An observational study', Australian Journal of Physiotherapy 52, 287-292. http://dx.doi.org/10.1016/S0004-9514(06) 70009-5

Nordin, N.A.M., Leornard, J.H.L. \& Thye, L.N., 2011, 'Work-related injuries among physiotherapists in public hospitals - A South Eastern picture', Clinics 66, 371-378.

Obembe, A.O., Onigbinde, A.T., Johnson, O.E., Emechete, A.A.I. \& Oyinlola, M.J., 2008, 'Occupational injuries among physical therapists in South-west Nigeria', Nigerian Journal of Medical Rehabilitation, 13(1\&2), 25.

South African Society of Physiotherapy, 2008, What is physio?, viewed 15 February 2013, from http://www.physiosa.org.za/?q=node/3

Simpson, M.R., 2006, 'Benign joint hypermobility syndrome: Evaluation, diagnosis, and management', Journal of American Osteopathic Association 106, 531-536.

Snodgrass, S.J. \& Rivett, D.A., 2002, 'Thumb pain in physiotherapists: Potential risk factors and proposed prevention strategies', Journal of Manual and Manipulative Therapy 10, 206-217. http://dx.doi.org/10.1179/106698102790819111

Thistlethwaite, A., 2005, 'Prevalence and perceived causes of thumb pain in female physiotherapists', Research report, Department of Physiotherapy, Durban University of Technology, Durban.

Useh, U., Igumbor, E.U. \& Madzivire, D.M., 2001, 'Occupational injuries among physiotherapists: A case study in Zimbabwe', viewed 10 January 2012, from http://www.unisa.ac.za/contents/faculties/humanities/sosw/docs/ASPJ-2003/ ASPJ2003-1-2-05-WHO-supported-injury-surveillance-activities-in-AfricaMozambique-and-Ethiopia.pdf

Wajon, A. \& Ada, L., 2003, 'Prevalence of thumb pain in physical therapists practicing spinal manipulative therapy', Journal of Hand Therapy 16, 237-244. http://dx.doi. org/10.1016/S0894-1130(03)00039-5

Wajon, A., Ada, L. \& Retshauge, K., 2007, 'Work related thumb pain in physiotherapists is associated with thumb alignment during performance of PA pressures', Manual Therapy 12, 12-16. http://dx.doi.org/10.1016/j.math.2005.09.003

Walsh, T., Delahunt, E., McCarthy Persson, U., 2011, 'Effects of taping on thumb alignment and force application during PA mobilizations', Manual Therapy 16 264-269. http://dx.doi.org/10.1016/j.math.2010.11.006

West, D.J. \& Gardner, D., 2001, 'Occupational injuries of physiotherapists in North and Central Queensland', Australian Journal of Physiotherapy 47, 179-186. http:// dx.doi.org/10.1016/S0004-9514(14)60265-8

Zancolli, E.A., Ziadenberg, C. \& Zancolli, E., 1987, 'Biomechanics of the trapeziometacarpal joint', Clinical Orthopaedic and Related Research 220, 14-26. http://dx.doi.org/10.1097/00003086-198707000-00004 